\title{
Article \\ Regulation of Ribosomal Protein Synthesis in Mycobacteria: The Autogenous Control of rpsO
}

\author{
Leonid V. Aseev, Ludmila S. Koledinskaya, Oksana S. Bychenko and Irina V. Boni *
}

Citation: Aseev, L.V.; Koledinskaya, L.S.; Bychenko, O.S.; Boni, I.V. Regulation of Ribosomal Protein Synthesis in Mycobacteria: The Autogenous Control of rpsO. Int. J. Mol. Sci. 2021, 22, 9679. https:// doi.org/10.3390/ijms22189679

Academic Editors: Alicja Wegrzyn and Grzegorz Wegrzyn

Received: 28 July 2021

Accepted: 3 September 2021

Published: 7 September 2021

Publisher's Note: MDPI stays neutral with regard to jurisdictional claims in published maps and institutional affiliations.

Copyright: (C) 2021 by the authors Licensee MDPI, Basel, Switzerland. This article is an open access article distributed under the terms and conditions of the Creative Commons Attribution (CC BY) license (https:// creativecommons.org/licenses/by/ $4.0 /)$.
Shemyakin-Ovchinnikov Institute of Bioorganic Chemistry RAS, 117997 Moscow, Russia; leroymail@gmail.com (L.V.A.); TchufistovaLS@yandex.ru (L.S.K.); bychenko.oksana@gmail.com (O.S.B.)

* Correspondence: irina_boni@ibch.ru or irinaboni@gmail.com

\begin{abstract}
The autogenous regulation of ribosomal protein (r-protein) synthesis plays a key role in maintaining the stoichiometry of ribosomal components in bacteria. In this work, taking the $r p s O$ gene as a classic example, we addressed for the first time the in vivo regulation of r-protein synthesis in the mycobacteria M. smegmatis (Msm) and M. tuberculosis $(M t b)$. We used a strategy based on chromosomally integrated reporters under the control of the rpsO regulatory regions and the ectopic expression of Msm S15 to measure its impact on the reporter expression. Because the use of E. coli as a host appeared inefficient, a fluorescent reporter system was developed by inserting $M s m$ or $M t b$ rpsO-egfp fusions into the Msm chromosome and expressing Msm S15 or E. coli S15 in trans from a novel replicative shuttle vector, pAMYC. The results of the eGFP expression measurements in $\mathrm{Msm}$ cells provided evidence that the $r p s \mathrm{O}$ gene in $\mathrm{Msm}$ and $\mathrm{Mtb}$ was feedback-regulated at the translation level. The mutagenic analysis showed that the folding of $\mathrm{Msm} r p s \mathrm{O} 5^{\prime} \mathrm{UTR}$ in a pseudoknot appeared crucial for repression by both Msm S15 and E. coli S15, thus indicating a striking resemblance of the rpsO feedback control in mycobacteria and in E. coli.
\end{abstract}

Keywords: mycobacteria; ribosomal proteins; autogenous regulation; shuttle vectors

\section{Introduction}

Bacterial ribosomes have been the targets of a majority of reported clinical antibiotics to date; hence, ribosome biogenesis and its regulation are central to the development of new antimicrobials. The biogenesis of ribosomes in bacteria is energetically costly as it requires the balanced synthesis of three rRNA molecules and multiple ribosomal proteins ( $\mathrm{r}-$ proteins) in stoichiometric amounts. Among the mechanisms maintaining the coordinated synthesis of ribosomal components, the role of the autogenous control of r-protein operons is widely recognized [1-4]. The ability of r-proteins synthesized in excess over rRNA to inhibit the expression of their own mRNAs has already been shown for most $E$. coli r-protein operons [2,3,5-8]. However, our knowledge of the r-protein-mediated regulation is based mainly on investigations conducted on E. coli and its close relatives in the $\gamma$-proteobacteria, or, to a lesser extent, on Bacilli, low-GC Gram-positive organisms. Almost no information is available for other bacterial phyla, including Actinobacteria, which are Gram-positive organisms with a high GC content. This phylum comprises many human pathogens, e.g., Mycobacterium tuberculosis and Mycobacterium leprae in the genus Mycobacterium, which highlights the importance of studies on the mechanisms of mycobacterial gene expression and its regulation.

One of the most thoroughly studied cases in the autogenous regulation of bacterial $\mathrm{r}$-proteins is the $\mathrm{rps}_{\mathrm{O}} \mathrm{O}$ gene-encoding r-protein uS15, a primary r-protein in the assembly of the $30 \mathrm{~S}$ ribosomal subunit. The details of the uS15-mediated autogenous control have been examined in numerous works dedicated to $r p s O$ expression regulation in E. coli [9-14], Bacillus stearothermophilus [15,16], Geobacillus kaustophilus [17], Thermus thermophilus [18], and Rhizobium radiobacter [19]. The rpsO regulation in all these cases operates at the translation initiation level through the binding of uS15 to specific regulatory structures 
in the $5^{\prime}$ untranslated region $\left(5^{\prime} \mathrm{UTR}\right)$ of the $r p s O$ mRNA, leading to the inhibition of translation, either by the ribosome "entrapment" in a non-productive complex (E. coli, see $[9,13,14])$ or by direct competition with the ribosome binding (Th. thermophilus, see [18]).

During the $30 \mathrm{~S}$ ribosome assembly, uS15 binds to a highly evolutionary, conserved central domain of the 16S rRNA. The interaction of uS15 with its rRNA target is well documented: The major contribution to binding is provided by the highly conserved three-helix junction (h20, h21, h22); this interaction is required for the subsequent binding of other proteins (e.g., bS6, bS18) necessary for the formation of the $30 \mathrm{~S}$ subunit platform. A relatively modest input is provided by the uS15 recognition of a universally conserved U-G/C-G motif in h22 ([12] and references therein). Unlike the high conservation level of the 16S rRNA targets for uS15, the regulatory structures within the $5^{\prime}$ UTRs of the $r p s O$ mRNAs widely vary both at the primary and secondary structure levels, suggesting a high S15-RNA interaction plasticity $[19,20]$. Thus, in E. coli, the extent of the similarity between the uS15 binding sites on $16 \mathrm{~S}$ rRNA and on its own mRNA is not high - the only signal common between the two targets is a U-G/C-G motif that contributes modestly to rRNA binding but is crucial for mRNA recognition. The E. coli regulatory site (operator) for S15 is a pseudoknot which is stabilized upon uS15 binding, thus preventing the formation of the active initiation complex [9-14]. In contrast, the operator structures for uS15 on the $B$. stearothermophilus and Th. thermophilus $r p s O \mathrm{mRNAs}$ are organized in three-way junction motifs, similar in the secondary (but not primary) structure to the respective 16S rRNA binding regions for uS15 $[15,16,18]$. The stabilization of the three-helix junction on the mRNA by uS15 binding may prevent the ribosome binding to initiate translation [18]. It is important to enlarge the list of regulatory structures on the natural $r p s O \mathrm{mRNAs}$ from other bacterial phyla in order to find the common signals providing autogenous regulation by uS15. Recently, a computational analysis of the $r p s O{ }^{\prime}$ UTRs predicted the presence of the conserved structural elements in Actinobacteria, indicating a high probability for $r p s O$ autogenous regulation in this phylum; however, this has not yet been confirmed experimentally [19].

In this article, taking the $r p s O$ gene as a classic example, we address the in vivo regulation of r-protein synthesis in M. smegmatis (Msm) and M. tuberculosis (Mtb). We used a previously developed strategy based on chromosomally integrated reporter genes under the control of the $r p s O$ regulatory regions and the ectopic expression of $\mathrm{Msm} \mathrm{S} 15$ to measure its effect on reporter expression. This approach allows for a quantitative evaluation of the impact of the excess r-protein on the efficiency of its own mRNA regulatory region. By using E. coli as a host, we demonstrated an inhibiting effect of Msm S15 in trans on the Msm $r p s \mathrm{O}^{\prime}$-'lacZ expression. However, expression of the Msm rpsO-lacZ reporter in E. coli turned out to be inefficient, necessitating the development of a cognate system based on Msm as an efficient host for mycobacterial gene expression [21]. We developed the fluorescence reporter assay by modifying the integrative shuttle vector pMV306 [22] in order to transfer the reporters $\mathrm{Msm}$ (or $\mathrm{Mtb}$ ) rpsO-egfp onto the $\mathrm{Msm}$ chromosome; to provide the expression of $M s m$ S15 in trans, we created a new E. coli-mycobacteria replicative shuttle vector, the pAMYC. The results of fluorescence measurements demonstrated that $\mathrm{Msm}$ and $\mathrm{Mtb}$ rpsO genes are negatively regulated by both Msm S15 and E. coli S15 at the translation level, thereby highlighting the similarity between mechanisms for S15-mediated autogenous control in E. coli and mycobacteria. According to the mutagenic analysis, a pseudoknot in the $5^{\prime} \mathrm{UTR}$ of the Msm mRNA is strictly required for regulation.

\section{Results and Discussion}

2.1. A Strategy for Using Escherichia coli as a Host for Studying the Autogenous Regulation of Mycobacterial r-Proteins

The post-transcriptional control of gene expression in Actinobacteria, including protein- or sRNA-mediated riboregulation, has been poorly investigated. Our main goal was to study the autogenous control of r-protein synthesis in mycobacteria. We started with the $r p s O$ gene, which was shown to be negatively regulated by its product, r-protein S15, in a range of different bacterial species (see Introduction). To study the in vivo regulation of 
rps O from M. smegmatis (Msm), a fast-growing nonpathogenic model of $M$. tuberculosis (Mtb), we first applied an approach based on chromosomally integrated $r p s O^{\prime}-{ }^{\prime} l a c Z$ reporters by using E. coli as a host. This methodology included the creation of the $r p s O^{\prime}-{ }^{\prime} l a c Z$ reporter under the control of the $M s m$ rpsO regulatory region on the plasmid pEMBL $\Delta 46$ [23] and its subsequent transfer onto the chromosome of a specialized E. coli strain ENS0 [23] by homologous recombination in order to provide a stable expression from a single-copy reporter gene. The use of E. coli as a host has previously been exploited to study the autogenous control of several r-protein operons from the $\gamma$-proteobacteria $[6,8,24,25]$, and of the $r p s O$ gene from B. stearothermophilus [16], but its applicability to bacterial phyla with a high GC content has not yet been corroborated. Given that the transcription and translation machineries of E. coli and mycobacteria have both common and significantly divergent features [26-33], it was difficult to predict in advance whether the expression of a certain mycobacterial gene in E. coli would be effective, as described in [29], or not. This needed to be experimentally verified.

\subsection{Comparison of Regulatory Regions of Mycobacterial and E. coli rpsO Genes}

The promoter and translation initiation regions (TIRs) of both M. smegmatis (Msm) and M. tuberculosis $(\mathrm{Mtb}$ ) rpsO genes resemble those of $E$. coli, though some details appear to be quite different (Figure 1A,B). While the promoter element -10 (consensus TANNNT) is present in mycobacterial $r p s O$, the consensus region -35 is not readily defined, which is typical of mycobacterial promoters [34,35]. At the same time, both $\mathrm{Msm}$ and $\mathrm{Mtb}$ rpsO promoters belong to the class of the extended -10 promoters (TGnTANNNT), which are recognized by E. coli RNA polymerase [26,36], albeit the absence of the conserved TTG in the region -35 (Msm) may have a negative impact on the promoter activity [36]. The initiator codon is a GUG in both the $\mathrm{Msm}$ and $\mathrm{Mtb} r p s \mathrm{O}$, while the $r p s \mathrm{O}$ coding region starts with an AUG in E. coli. It is known that a GUG is used more often in mycobacteria than in E. coli [34], but given that several E. coli genes (e.g., rpsM encoding the r-protein uS13) show a high expression level with a GUG start codon, a combination of the rpsO GUG with a canonic Shine-Dalgarno (SD) element (GGAG in Msm, Mtb, and E. coli) may be estimated as recognizable by the $E$. coli ribosome during translation initiation.

A

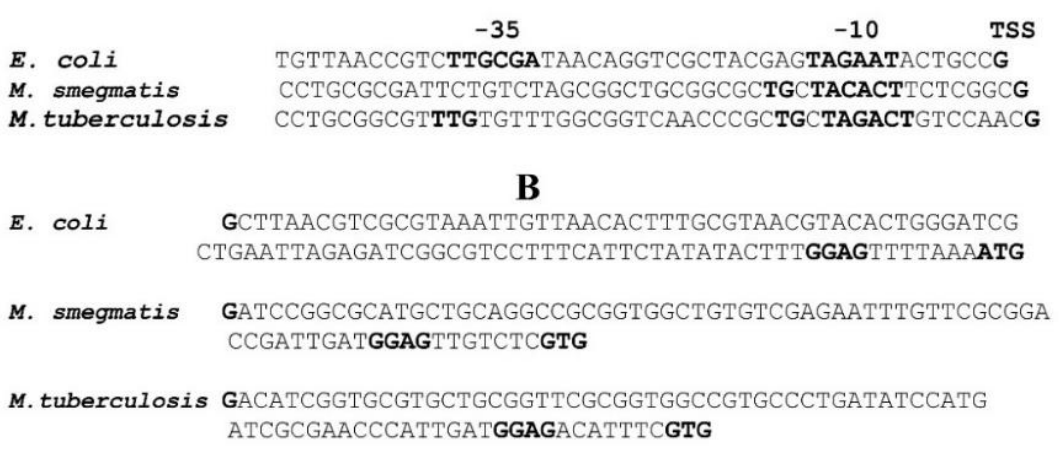

Figure 1. Cont. 

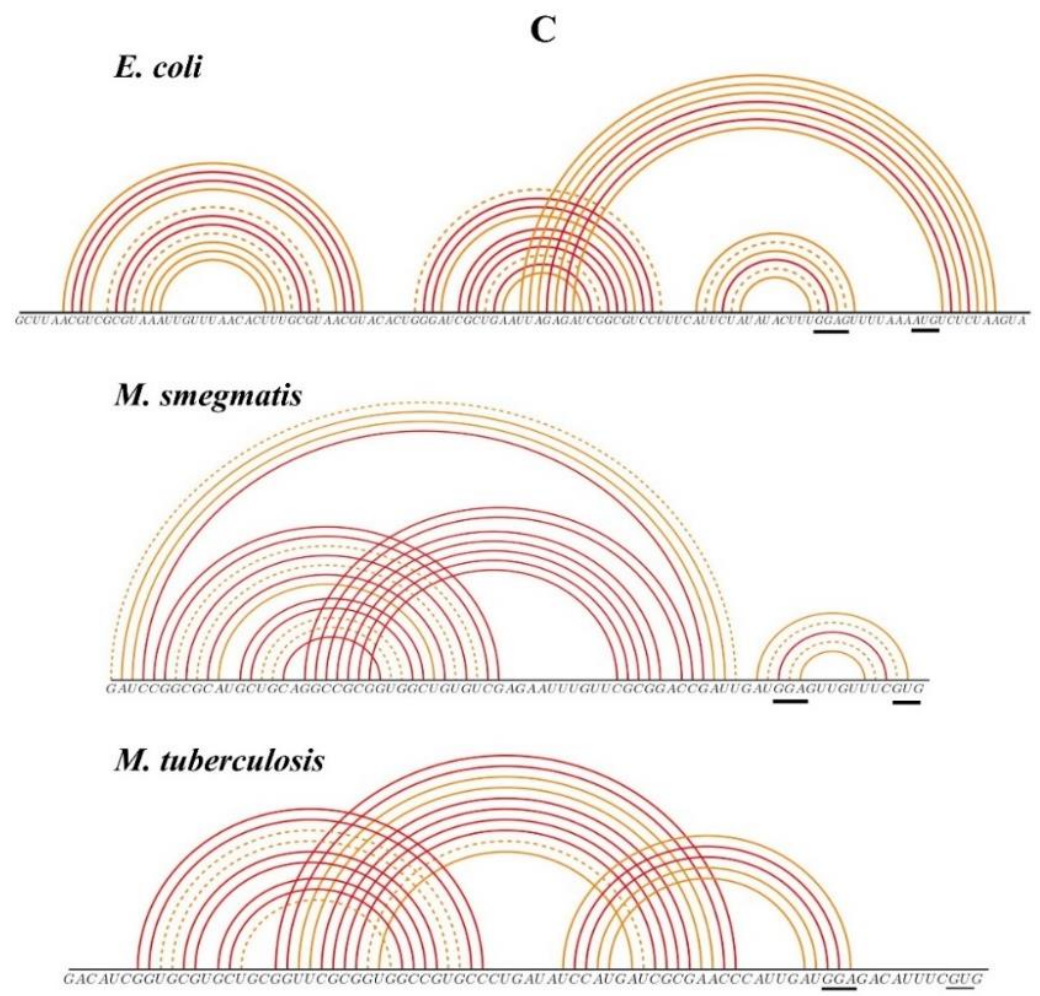

D

TGACGCGGTCCTAGGTGGGAACCACATCCGCGGCCGTCCTCGGGGCGGCCGCGGTTCTTTCTTT

Figure 1. Regulatory elements in front of the $r p s O$ coding region in E. coli, M. smegmatis, and M. tuberculosis. (A,B) Comparison of the core rpsO promoters (A) and $5^{\prime}$ UTRs (B). The TSS (transcription start site), $-10,-35$ promoter regions (A) as well as the initiator codon and the Shine-Dalgarno element (B) are in bold. (C) 5'UTRs of E. coli, Msm, and Mtb rpsO mRNAs are able to form pseudoknots (according to [37]); the most stable structures are shown as pairing probability arcs. (D) Presumable intrinsic transcription terminator of the $\mathrm{Msm}$ rpsO gene; complementary sequences forming a hairpin structure are underlined.

\subsection{The rpsO Promoter from $M$. smegmatis Is Inoperative in E. coli}

Following the strategy described above, we constructed the chromosomally integrated reporter Msm rpsO'-'lacZ under the control of the $\mathrm{Msm} r p s O$ promoter and the TIR (Figure 2A). Although we managed to obtain the $\mathrm{Lac}^{+}$phenotype resulting from homologous recombination, the $\beta$-galactosidase assay showed a very low expression output that was insufficient for statistically reliable measurements. To increase the expression level, we exchanged the $\mathrm{Msm} r p s O$ promoter for the promoter of $E$. coli rpsO while preserving the $\mathrm{Msm} \mathrm{rpsO} \mathrm{5}^{\prime} \mathrm{UTR}$ intactness, which is indispensable for studying $\mathrm{Msm}$ rpsO autogenous regulation. The resulting construct showed a ca. 10-fold higher expression level (Figure 2B), thus allowing us to evaluate the impact of Msm S15 in trans on the Msm rpsO-lac Z expression.

To find the optimal construct for the $\mathrm{Msm} \mathrm{rpsO}$ ectopic expression, we generated three versions of the plasmid pS15 ${ }_{M s m}$ (Figure 2C). First, using pACYC184, we cloned the whole gene $\mathrm{Msm} r p s \mathrm{O}$ with its native flanks, including the promoter, $5^{\prime} \mathrm{UTR}$, and the transcription terminator (version 1); in version 2, the $\mathrm{Msm} r p s O$ promoter was exchanged for the E. coli counterpart, with the Msm rpsO 5'UTR remaining intact; finally, in version 3, we replaced not only the $\mathrm{Msm} r p s \mathrm{O}$ promoter, but also the $5^{\prime} \mathrm{UTR}$ and the initiator GUG with the E. coli $r p s O$ promoter, $5^{\prime} \mathrm{UTR}$, and the initiator AUG (Figure $2 \mathrm{C}$ ). 


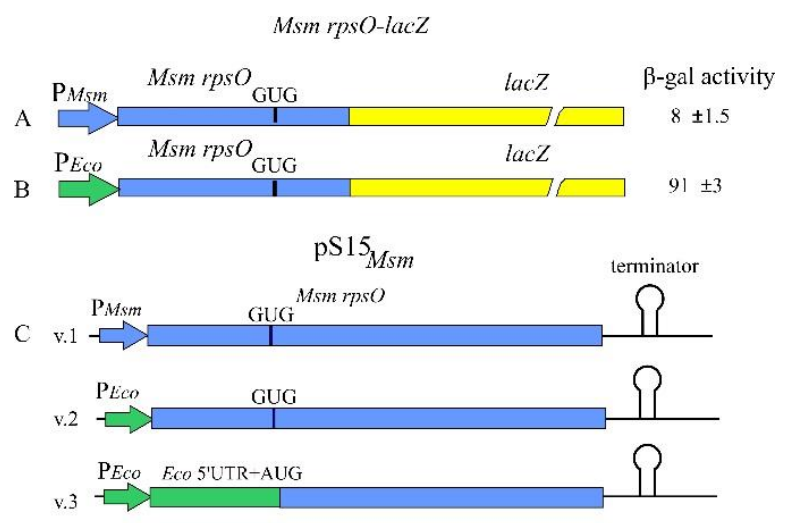

D

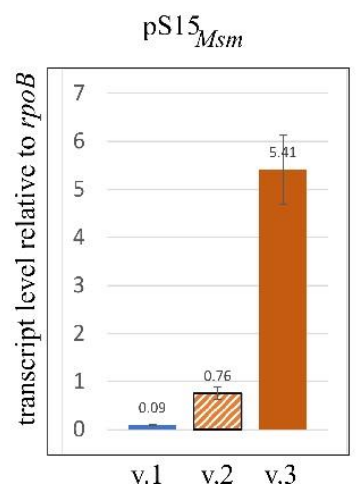

Figure 2. Constructs for studies of the Msm rpsO autoregulation by using E. coli as a host. (A) Msm $r p s \mathrm{O}^{\prime}$-'lacZ fusion under the Msm rpsO promoter. (B) Msm rpsO'-'lacZ fusion under the E. coli rpsO promoter. Corresponding $\beta$-galactosidase activities are indicated. (C) Three versions of pS15 $5_{M s m}$ plasmid (v.1, v.2, v.3) for the expression of Msm S15 in trans. (D) Msm rpsO transcript levels in E. coli cells bearing three versions of $\mathrm{pS} 15_{M s m}$. The results of RT-qPCR analysis, with rpoB as an internal control. Transcript amounts relative to $r p o B$ are indicated above the bars.

The efficiency of the $\mathrm{Msm} r p s \mathrm{O}$ gene expression from the constructed plasmids (pS15 Msm versions 1, 2, and 3) was evaluated by measuring the Msm rpsO transcript level in E. coli cells by using RT-qPCR, with the rpoB transcript serving as an internal standard (Figure 2D). The highest level of the Msm rpsO transcript was found in cells bearing $\mathrm{pS}_{15} \mathrm{Msm}_{\mathrm{v}} \mathrm{v} .3$, where the synthesis of $\mathrm{Msm} \mathrm{S} 15$ was driven by the regulatory regions of the E. coli $r p s O$. The plasmid pS15 ${ }_{M s m}$ v.1 (Msm rpsO promoter, Msm rpsO 5'UTR) showed the lowest transcript yield (Figure 2D), in line with the low expression output of the Msm $r p s O^{\prime}$-'lacZ reporter. More importantly, the change of only the $M s m$ rpsO promoter for the E. coli counterpart ( $\mathrm{pS} 15_{\mathrm{Msm}} \mathrm{v} .2$ ) significantly increased the transcript level, suggesting that the mycobacterial rpsO promoter is inoperative in E. coli.

Interestingly, not only the promoter region but also the $5^{\prime} \mathrm{UTR}$ structure had a significant impact on the transcription output. A comparison of the $M s m$ rpsO transcript levels for cells bearing $\mathrm{pS} 15_{\mathrm{Msm}} \mathrm{v} .2$ and $\mathrm{pS} 15_{\mathrm{Msm}} \mathrm{v} .3$ revealed a seven-fold increase, indicating that the transcription and hence overall expression of the GC-rich $M s m$ rpsO coding sequence become more efficient with the E. coli $5^{\prime} \mathrm{UTR}$, despite the presence of the same E. coli rpsO promoter (Figure 2D). We suppose that the cognate E. coli rpsO TIR provides much more effective ribosome loading during translation initiation, thereby ensuring the efficient transcription-translation coupling necessary for the synthesis of a stable transcript $([38,39]$ and references therein). Furthermore, it has been shown that the r-protein bS1 plays a key role in the recognition and binding of mRNA $5^{\prime}$-UTRs by the $E$. coli $30 \mathrm{~S}$ ribosomal subunit during initiation complex formation [40,41], including the structured $r p s O \mathrm{mRNA}$, forming a pseudoknot that should be melted by bS1 in order to accommodate the rpsO TIR on the $30 \mathrm{~S}$ ribosome [42]. As shown recently, the ability of bS1 to unfold pseudoknots inversely 
correlates with their structural stability [43]. This may suggest that the Msm rpsO 5'UTR able to form a stable pseudoknot (Figure 1C) represents an arduous target for E. coli S1. In addition, it has been demonstrated that the E. coli S1 capacity to recognize $5^{\prime} \mathrm{UTRs}$ of high GC-mRNAs is limited, so that the high GC content of heterologous mRNAs presents a significant challenge to $E$. coli ribosomes when initiating translation [44]. This was supported by the directed evolution of E. coli S1, resulting in the selection of S1 mutants capable of enhancing the translation of GC-rich mRNAs by E. coli ribosomes [44]. We suppose that the limited ability of E. coli $\mathrm{S} 1$ to recognize and unfold structured GC-rich sequences within $5^{\prime} \mathrm{UTRs}$ is most likely one of the main reasons behind the low expression level of the Msm $r p s O$ mRNA in E. coli.

\subsection{The Msm rpsO'-'lacZ Reporter Is Regulated by Both Msm and E. coli S15}

Based on the above observations (Figure 2D), the plasmid pS15 ${ }_{M s m} \mathrm{v} .3$ was chosen for subsequent studies of the $\mathrm{Msm} r p s \mathrm{O}$ autogenous control. The $E$. coli cells bearing the Msm rpsO'-'lacZ reporter under the control of the E. coli rpsO promoter (Figure 2B) were transformed with the pS15 ${ }_{M s m} \mathrm{v} .3$ or with an empty vector, and the $\beta$-galactosidase levels were measured in transformants. Although the expression of the reporter was not high, the use of five or more biological replicates allowed us to obtain statistically reliable results which revealed ca. six-fold repression in the presence of $\mathrm{pS} 15_{\mathrm{Msm}} \mathrm{v} .3$, thus clearly indicating the feedback regulation of the $\mathrm{Msm} r p s \mathrm{O}$ mRNA (Figure 3A). The repression level was about the same as that for $E$. coli rpsO in the presence of $\mathrm{pS}_{\mathrm{E}} 5_{E c o}$, even though the expression of the Eco rpsO-lacZ reporter was incomparably higher (Figure 3B).

Intriguingly, $\mathrm{pS} 15_{E c o}$ was also able to inhibit the expression of the $\mathrm{Msm} r p s \mathrm{O}^{\prime}$-'lacZ reporter, with the repression level being a little lower (Figure $3 \mathrm{~A}$ ). At the same time, pS15 ${ }_{\mathrm{Msm}} \mathrm{v} .3$ only had a marginal impact on the expression of Eco rps $\mathrm{O}^{\prime}$-'lacZ (Figure 3B), indicating that despite a high homology level (Figure 3C), Msm S15 is not capable of recognizing the $E$. coli rps O operator, whereas E. coli S15 has the ability to bind the heterological rpsO $5^{\prime} \mathrm{UTR}$ and to inhibit translation. To find out the underlying cause for this effect, we compared a set of amino acid residues for E. coli S15 reportedly involved in the recognition of the operator site (a pseudoknot) with residues of Msm S15 in the same positions (Figure 3D). It is well-established that $E$. coli S15 recognizes two sites on the pseudoknot, a U-G/C-G motif in stem 1 and the A-46 in loop 1 (Figure $4 \mathrm{~A}$ ), which are equally essential for the feedback regulation [11-13]. The U-G/C-G motif is recognized by the His42, Asp 49, and Ser52 of E. coli S15, while Arg58 is strictly required for the A-46 recognition, so that its exchanges for other amino acid residues impair autogenous regulation [13].

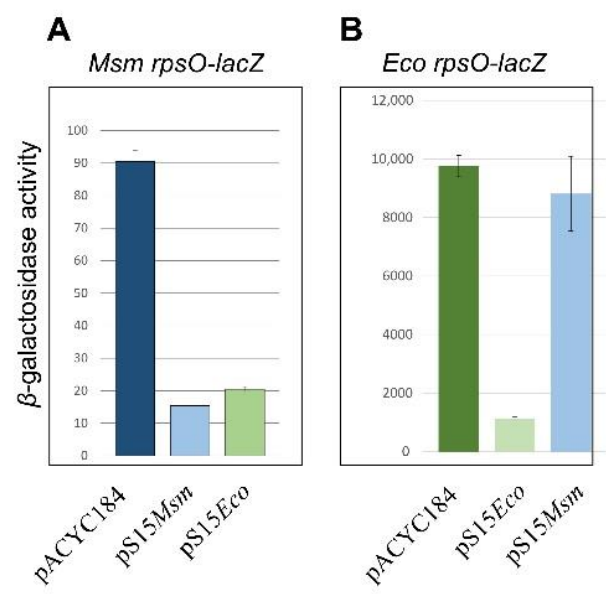

Figure 3. Cont. 


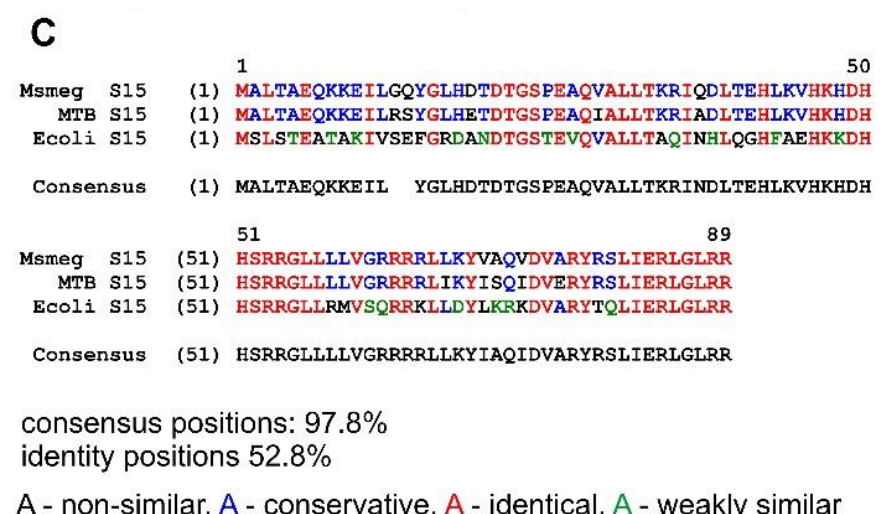

A - non-similar, A - conservative, A - identical, A - weakly similar

D

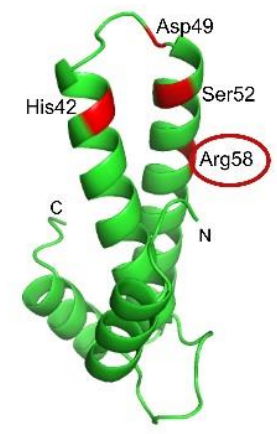

E. coli $\mathrm{S} 15$

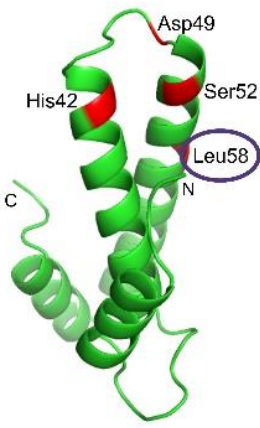

Msm $\mathrm{S} 15$

Figure 3. The $\mathrm{Msm} r p s O$ gene is feedback-regulated at the translation level, similar to E. coli rpsO. (A) Inhibition of the Msm rpsO-lacZ reporter expression in the presence of Msm S15 and E. coli S15 in trans. (B) Autogenous regulation of the E. coli rpsO-lacZ reporter: E. coli $\mathrm{S} 15$ in trans inhibits expression, while Msm S15 only has a marginal effect. (C) Alignments of S15 sequences from E. coli, $M s m$, and Mtb. (D) Three-dimensional structures of free S15 from E. coli and Msm as predicted by IntFOLD [45]; amino acid residues reported to be involved in mRNA binding by E. coli S15 [13] are shown.

It should be mentioned that in a paper by Mathy et al. [13], the numbering of amino acid residues is different (His41, Asp48, Ser51, Arg57), as Met1 is not counted because it splits off after protein synthesis. Since we have no information about the fate of the first methionine in mycobacterial proteins, we counted all residues, including Met1 on Figure 3D. As one can see, Msm S15 has the same set of amino acids involved in the binding of the U-G/C-G motif, but it possesses Leu58 instead of Arg58. This difference might explain the absence of the inhibitory effect of $\mathrm{Msm} \mathrm{S} 15$ on the E. coli rpsO-lacZ expression (Figure 3B).

More importantly, just as the E. coli regulatory region, the Msm rpsO $5^{\prime}$ UTR can be folded in two topologically distinct conformations-two stem-loops and a pseudoknot (Figure 4A,B). In E. coli, uS15, acting as a repressor, recognizes only a pseudoknot. By comparing the structure predicted for the $M s m r p s O 5^{\prime} \mathrm{UTR}$ with the well-established $E$. coli pseudoknot, a striking resemblance is clearly visible (Figure $4 \mathrm{~A}, \mathrm{~B}$ ), including the $\mathrm{A}$ in loop 1. Although the Msm loop 2 that bridges the two stems is shorter than the E. coli loop 2 , it is long enough (10 nts) to be recognized by E. coli S15, as it was shown that loop 2 could be reduced without a loss of the regulation, but not below nine nucleotides [12]. Given the visible analogy to the well-studied S15-mediated translational regulation in E. coli, we assume that Msm S15 has an ability to inhibit its own translation through a feedback regulatory mechanism at the translation level, such as that in E. coli. 
A

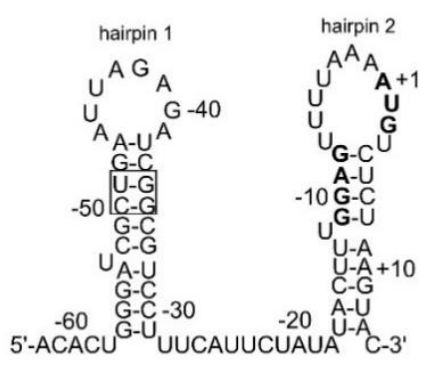

Eco rpsO 5' UTR

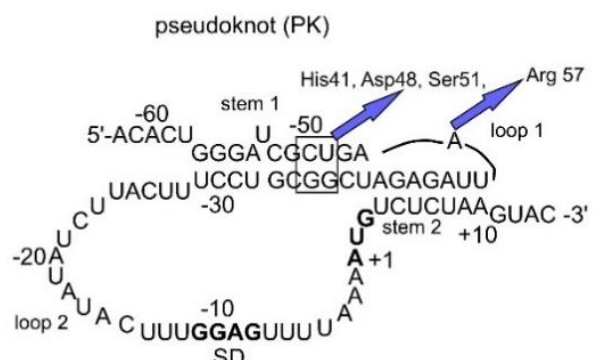

B

Msm rpsO 5' UTR

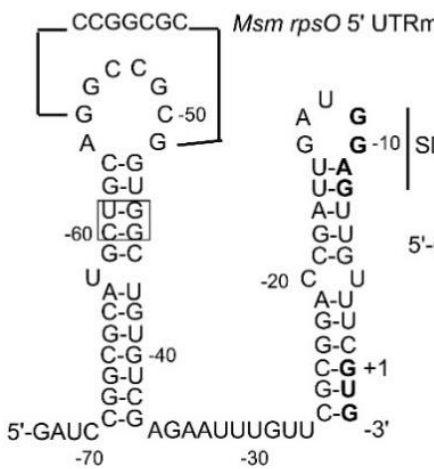

Rmut (no PK)
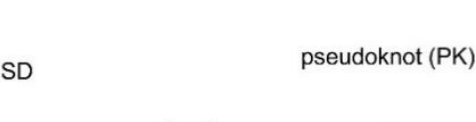

5'-GAUC ${ }_{\text {CGGCGCA }}{ }^{-60}$ loop 1

${ }_{\text {CGGCGCA GCUGC }}^{-60}$ GCUGUGU QGGUGGCGCC GG A

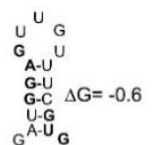

${ }^{G} A$ A $\cup \cup \cup G \cup \cup \cup_{-20}^{-40}{ }_{-10}$

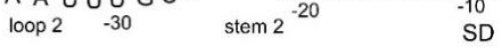

C

Mtb rpsO 5' UTR

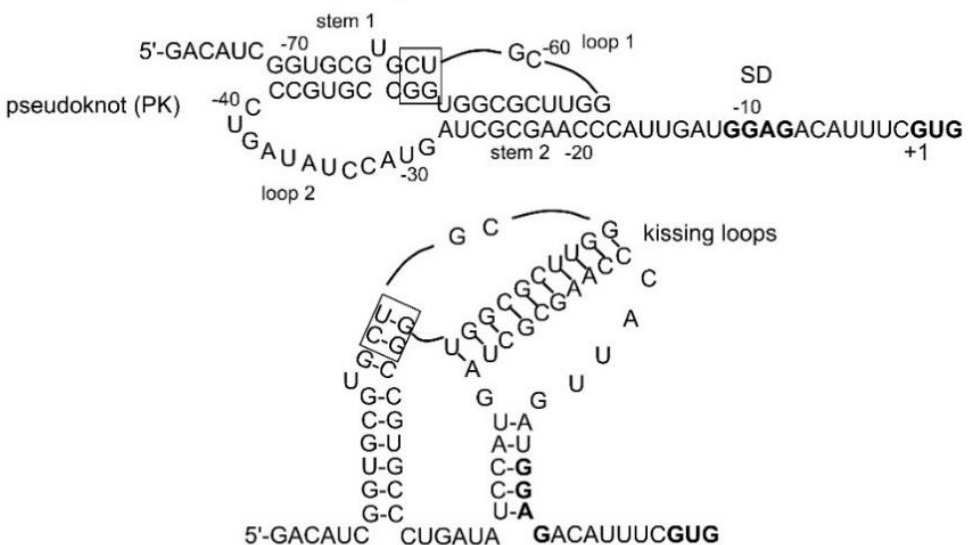

Figure 4. Comparison of the well-studied operator structure for E. coli rpsO (A), with predicted rpsO $5^{\prime}$ UTR structures for Msm (B) and Mtb (C). The style of presentation is adopted from [46] as it allows for the revelation of more obvious similarities and differences in the RNA folds. Initiator codons and SD sequences are in bold, and a conserved U-G/C-G motif is framed. (A) Two topologically distinct conformations of the E. coli rpsO regulatory site-two stem-loops (hairpins 1 and 2) and a pseudoknot. The uS15 recognizes two sites in the pseudoknot (shown by blue arrows); respective amino acid residues involved in recognition according to [13] are indicated. (B) Two predicted conformations of the $\mathrm{Msm} r p s \mathrm{O} 5^{\prime} \mathrm{UTR}$ (two hairpins and a pseudoknot) have a strong resemblance to the E. coli rpsO 5'UTR structures. Changes able to prevent the pseudoknot formation are shown above hairpin 1. A small hairpin shown above the ribosome binding site was predicted to exist in the most stable variant of the $\mathrm{Msm}$ rpsO pseudoknot structure (Figure 1C). (C) Predicted secondary structures for the $\mathrm{Mtb} r p s O 5^{\prime} \mathrm{UTR}$ (see Figure 1C): a pseudoknot bears resemblance to the Msm rpsO pseudoknot but may become more compacted by forming a structure of "kissing loops". 


\subsection{Creation of the Cognate System for Studying the Autogenous Control of r-Protein Synthesis in Mycobacteria}

The low expression output of the Msm rpsO'-'lacZ reporter revealed obvious limitations of using $E$. coli as a host to study the autogenous control of mycobacterial r-proteins. Indeed, to enable the constructs to provide a measurable efficiency of the reporter integrated in the chromosome, we had to exchange the mycobacterial $r p s O$ promoter for the $E$. coli counterpart. Furthermore, to provide the efficient expression of Msm S15 in trans, we had to substitute the regulatory region, including the promoter $5^{\prime} \mathrm{UTR}$ and the start codon, for respective E. coli determinants. In addition, as uS15 is a small protein (89 amino acid residues), the expression of the $\mathrm{Msm} r p s O$ short coding region in E. coli did not appear to be a very difficult task for the transcription/translation machineries of $E$. coli even though they had been adapted to a lower GC content. It is reasonable to suspect that the mycobacterial mRNAs encoding longer r-proteins (such as RpsA, RpsB) will bring far more problems, making the use of E. coli as a host unpromising for future studies. Thus, it is vital to develop the authentic system for studies of the r-protein-mediated control in mycobacteria, and $M$. smegmatis represents the best proxy for such experiments [21].

Both integrative (to be inserted into mycobacterial chromosome) and replicative (for ectopic expression of genes under study) plasmids for creating the Msm-based reporter system were reported [22] and widely used. The integrative plasmid pMV306hsp was initially derived from a replicative vector pMV261 by replacing the mycobacterial replication origin (oriM) with a DNA fragment comprising the attachment site attP and the integrase gene int from the mycobacteriophage L5, which provided a site-specific integration into the chromosomal attB site [22]. In addition, this vector carries the $h s p 60$ promoter and the $r r n B$ terminator to facilitate the cloning and expression of different genes as a single copy integrated into the chromosome. We modified pMV306hsp by replacing the region comprising the $h s p$ promoter with the $\mathrm{Msm}$ rpsO-egfp reporter bearing the $\mathrm{Msm}$ rpsO core promoter and $5^{\prime}$ UTR in front of the eGFP coding sequence, so that the transcription of the reporter gene would be governed by the $r p s O$ core promoter and terminate at the $r r n B$ terminator (Figure 5A).

\subsection{The Msm rpsO Core Promoter Requires an Upstream Region to Enhance the Transcription Yield}

To evaluate the efficiency of the chromosomally integrated fluorescent reporter, the Msm cells $\left(\mathrm{kan}^{\mathrm{r}}\right)$ were harvested at the exponential phase $\left(\mathrm{OD}_{600} \sim 0.7-0.8\right)$ and then disintegrated for the preparation of protein lysates to be used for measuring the fluorescence of the reporter. The fluorescence appeared unexpectedly low despite the fact that ribosomal core promoters, at least in $E$. coli, are generally effective (e.g., the $r p s O$ promoter in a fusion Eco_rpsO-lacZ, see Figure 3B). An analysis of the published data revealed that, in contrast to $E$. coli, mycobacterial core promoters (including only -10 and -35 promoter regions) may be inefficient, requiring $5^{\prime}$ extensons to augment their strength $[27,47,48]$. In particular, the core $\mathrm{Msm} r \mathrm{rnB}$ promoter (which a priori should be one of the strongest in bacterial cells) remained relatively weak unless and until the upstream region was significantly extended [27]. To test whether it is also the case with the $r p s O$ gene, we extended the $r p s O$ promoter sequence (the initial $5^{\prime}$ edge was at position -47 from TSS) to obtain the $5^{\prime}$ extended variants: version $2(-117)$ and version $3(-231)$, and then created the Msm cells bearing the corresponding rpsO-egfp reporters in the chromosome (Figure 5A). The fluorescence measurements revealed the increased yield of eGFP in the extended promoter variants (Figure 5B). The same was previously shown for the Msm rrnB and Ms1 promoters [27,47]. The exact mechanism for the enhancement of transcription efficiency upon promoter extension has not yet been clarified. The $\mathrm{Msm} r p s \mathrm{O}$ gene is transcribed from a single promoter [49,50]; hence, the impact of additional upstream promoters on transcription yields is unlikely. One of the reasonable explanations is the existence of upstream binding sites for yet unknown transcription factors acting as activators [27,47]. Based on the experimental observations, we used the Msm rpsO-egfp fusion bearing the -231 extension for further experiments. 
A

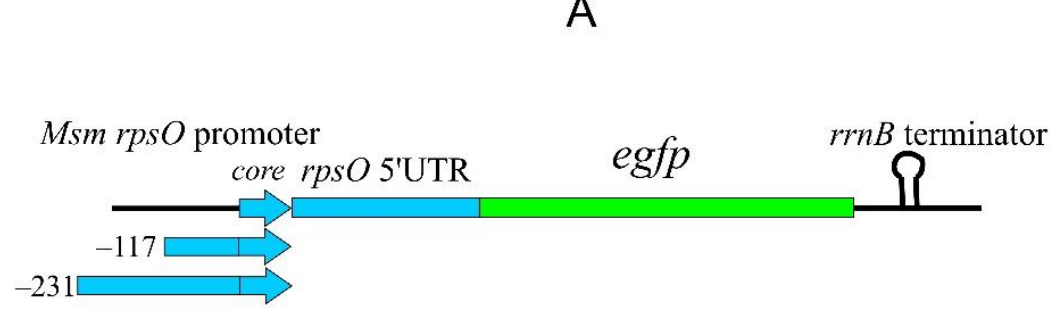

B

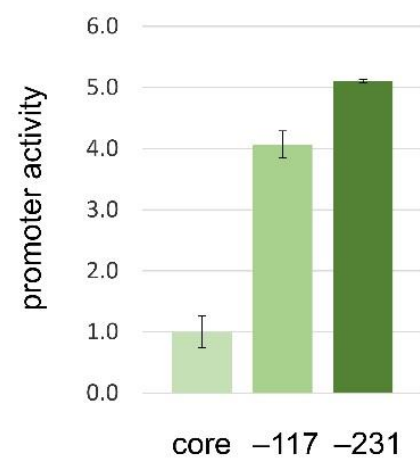

Figure 5. The expression level of the chromosomally integrated $\mathrm{Msm} r p s \mathrm{O}-\mathrm{eg} f \mathrm{p}$ reporter depends on the $5^{\prime}$-extension of the $\mathrm{Msm}$ rpsO promoter. (A) Msm rpsO-egfp reporters with different $5^{\prime}$ extensions within the Msm chromosome. (B) Results of fluorescent measurements of protein lysates obtained from exponential Msm cells bearing rpsO-egfp reporters governed by the $r p s O$ promoters with different $5^{\prime}$ extensions; positions of relative TSS are indicated, with "core" corresponding to the $5^{\prime}$ edge position -47 . Fluorescence (average of at least three biological replicates) of the protein samples corresponding to the core promoter construct is taken as a unit.

\subsection{Generation of the Novel Replicative Shuttle Vector, pAMYC}

To provide the ectopic expression of the $\mathrm{Msm} r p s \mathrm{O}$ gene necessary to study the S15mediated effect on the efficiency of the $r p s O-e g f p$ reporter, we created a novel shuttle replicative vector, $\mathrm{pAMYC}$, by transferring the region comprising the mycobacterial replication origin from pMV261 to pACYC184 (Figure 6). The vector pMV261 itself is not applicable because it bears the same kanamycin-resistant marker as an integrative pMV306 used for the incorporation of the $r p s \mathrm{O}-\mathrm{e} g \mathrm{fp}$ fusion into the $\mathrm{Msm}$ chromosome. The electroporation of the novel shuttle plasmid pAMYC into Msm cells yielded chloramphenicol-resistant transformants, indicating its suitability for the ectopic expression of different mycobacterial genes (Figure 6).

\subsection{Mycobacterial rpsO Expression Is Feedback-Regulated at the Translation Level}

To facilitate the synthesis of Msm S15 in trans, we cloned the $M s m$ rpsO gene bearing the $5^{\prime}$-extended promoter variant $(-231)$ and its own intrinsic terminator into pAMYC. The resulting plasmid pAMS15 ${ }_{\mathrm{Msm}}$ was used to transform $\mathrm{Msm}$ cells bearing the chromosomal $r p s O$-e $g f p$ fusion under the same $5^{\prime}$-extended $(-231) r p s O$ promoter. An empty pAMYC served as a control. Exponential Msm cells were harvested and disintegrated to prepare protein lysates where the eGFP fluorescence was measured. The results clearly showed the reduced fluorescence in cells bearing pAMS15 ${ }_{M s m}$ when compared to the control cells bearing an empty pAMYC (Figure 7A), thus indicating that uS15 in trans down-regulates the reporter expression. This strengthens the results obtained with $E$. coli as a host. Just as in E. coli (Figure 3A), Msm S15 in trans also had an inhibitory effect on the Msm rpsO-egfp expression (Figure 7A). 


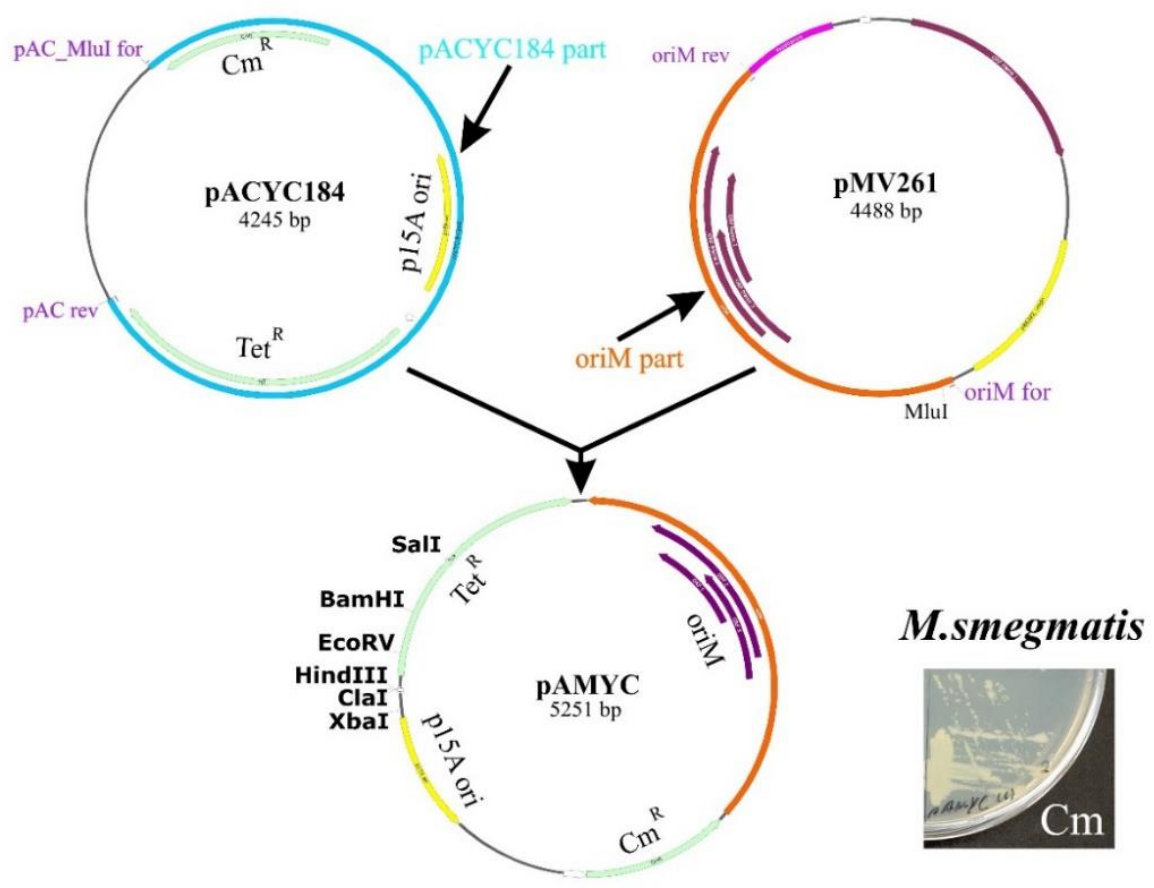

Figure 6. The scheme for creating the novel replicative shuttle vector, pAMYC, a derivative of pACYC184. Transformation of M. smegmatis by pAMYC results in the appearance of chloramphenicolresistant colonies on LB-Cm plates.

Furthermore, we created an analogous, chromosomally integrated reporter where the eGFP expression was under the control of the extended (-158) promoter and the $5^{\prime} \mathrm{UTR}$ of the $\mathrm{M} t b \mathrm{rpsO}$ gene. The fluorescence was measured for the Msm cells bearing the pAMYC derivative expressing $M s m$ S15 (which is $88.8 \%$ identical to the Mtb S15) or E. coli S15, and an empty vector as a control. The results clearly showed the repression of the $M t b$ rpsO-egfp expression by both Msm S15 and E. coli S15 in trans (Figure 7B). Taken together, the results allow us to conclude that mycobacterial $r p s O$ expression is feedback-regulated at the translation level, and that the mechanism likely resembles that of E. coli. Most probably, acting as a repressor, uS15 binds the $5^{\prime}$ UTRs of the Msm and Mtb rpsO mRNAs folded into pseudoknots (Figure 4B,C), thereby stabilizing its structure and impeding ribosome loading to initiate translation. For instance, the $M t b 5^{\prime} \mathrm{UTR}$ may be stabilized by $\mathrm{S} 15$ in a compacted "kissing loops" structure, which hides the SD sequence from ribosome binding (Figure 4C).

\subsection{The Pseudoknot in the Msm rpsO 5'UTR Is Essential for the Autogenous Control}

To obtain direct proof of the essential role of pseudoknot formation in the feedback control of the $\mathrm{Msm} r \mathrm{rsO}$ expression, we mutagenized the sequence involved in the pseudoknot by exchanging the GGCCGCG for the CCGGCGC (Figure 4B). This should destroy the stem 2 in a pseudoknot, such that the $5^{\prime}$ UTR could only form a double hairpin conformation. The mutated variant of the Msm rpsO-egfp (mutPK) reporter was incorporated into the Msm chromosome, and fluorescence was measured in the corresponding cells in the presence of Msm S15 or E. coli S15 in trans vs. an empty vector. The data obtained (Figure 7C) clearly show the total absence of the S15-mediated repression (by both Msm S15 and E. coli S15) accompanied by reduced expression efficiency (compare Figure 7A,C). This suggests that a pseudoknot structure in the $5^{\prime} \mathrm{UTR}$ of the $\mathrm{Msm} r p s O \mathrm{mRNA}$ is preferentially recognized both by $\mathrm{S} 15$ as an autogenous repressor and by the ribosome during translation initiation. The mutated Msm rpsO 5'UTR in a double harpin conformation hides the initiator GUG and partly the SD-sequence from ribosome recognition (Figure 4B), thereby reducing the efficiency of translation initiation. E. coli S15 acts largely in a similar way (Figure 7C), thus 
allowing us to conclude that the mycobacterial autogenous control of the $r p s O$ expression bears close resemblance to that of $E$. coli despite the large phylogenetic distance between Gram-negative gamma-proteobacteria and high GC Gram-positive mycobacteria.

A

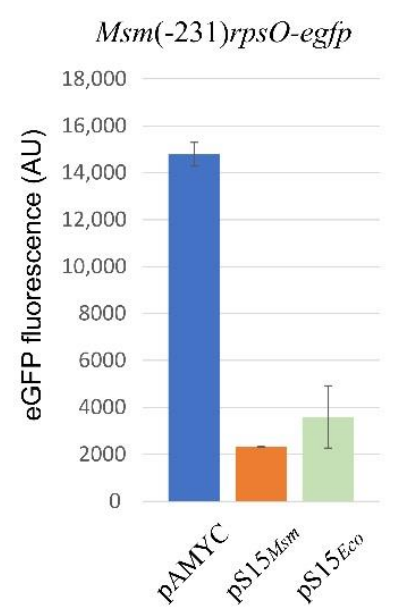

B

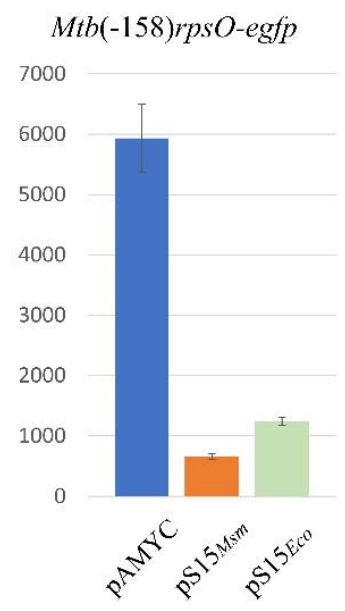

C

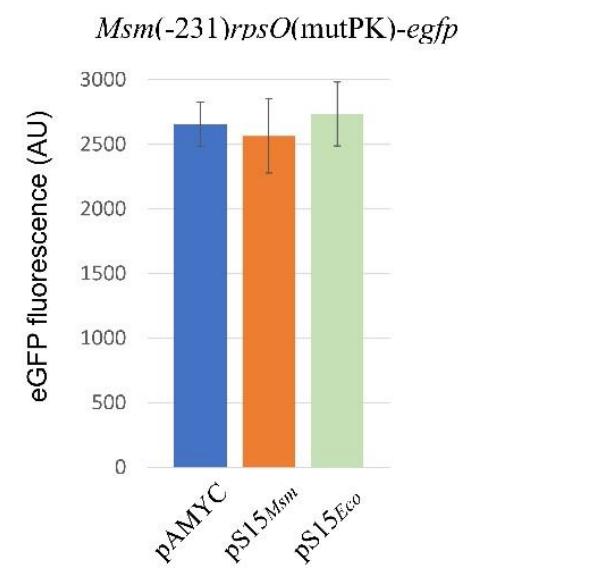

Figure 7. The $r p s O$ genes of $M$. smegmatis and $M$. tuberculosis are feedback-regulated in vivo at the translation level. Repression of the Msm rpsO-egfp (A) and Mtb rpsO-egfp (B) expression in the presence of the pAMYC derivative expressing Msm S15 and E. coli S15. Results of fluorescent measurements of protein lysates from at least three biological replicates. (C) The pseudoknot is crucial for the regulation of the Msm rpsO-egfp reporter; changes preventing its formation (see Figure 4B) abolish the feedback regulation.

\subsection{Concluding Remarks}

In this work, we provided evidence that the autogenous control of r-protein synthesis at the translation level functions in mycobacteria. We developed a reporter system based on M. smegmatis, which is suitable for the study of the regulation of mycobacterial genes that encode r-proteins. The use of E. coli as a host for this purpose was found unpromising because of the low efficiency of the $E$. coli transcription/translation machinery in the expression of mycobacterial genes. To study the regulation of the $r p s O$ gene encoding $\mathrm{r}-$ protein S15, we obtained the Msm cells bearing the reporters Msm_rpsO-egfp and Mtb_rpsOegfp in the chromosome and measured their activity in the presence of Msm S15 expressed from the new replicative shuttle plasmid pAMYC vs. an empty vector. The inhibition of the reporter expression by MsmS15 in trans clearly indicated the autogenous control of the rps $O$ expression in mycobacteria.

The most important finding is that the autogenic regulation of the mycobacterial $r p s O$ genes strictly required the pseudoknot conformation of the $5^{\prime} \mathrm{UTR}$, so that the mutagenesis of the sequence involved in the formation of the pseudoknot completely abolished the 
S15-mediated repression. Moreover, E. coli S15 was also found to be capable of acting as a repressor of the $M s m / M t b r p s O$ expression, and this ability was lost when the pseudoknot structure within the $5^{\prime} \mathrm{UTR}$ was destroyed by mutations. This provides evidence that the mechanism for the S15-mediated autogenous control in mycobacteria bears close resemblance to that described for $E$. coli despite the large phylogenetic distance between these bacterial species. In other words, the involvement of the pseudoknot in the S15mediated autogenous regulation is not only specific for E. coli but may have independently emerged in distant mycobacterial species.

\section{Materials and Methods}

\subsection{Strains and Plasmids}

Strains and plasmids used in this study are listed in Table 1. Mycobacterium smegmatis $\mathrm{mc}^{2} 155$ [51] was provided by Prof. A. S. Kaprelyants (Bach Institute of Biochemistry, Moscow, Russia). Isolation of M. smegmatis genomic DNAs was performed according to Belisle et al. [52]. M. tuberculosis genomic DNA was a kind gift from Dr. E. Salina (Bach Institute of Biochemistry, Moscow, Russia). For experiments with E. coli as a surrogate host, plasmids $\mathrm{pS} 5_{\mathrm{Msm}}$ (versions 1, 2, 3), derivatives of the pACYC184 cloning vector, were constructed to express in trans the rpsO gene from M. smegmatis (Msm). The plasmid pEMsm_rpsO-lacZ, a derivative of pEMBL $\Delta 46$ [23] bearing the $M s m$ rps $O^{\prime}$-'lacZ fusion, was used to transfer this reporter onto the chromosome of ENS0 by homologous recombination. For the M. smegmatis expression system, the derivatives of the pMV306 integrative plasmid bearing the kanamycin-resistant marker [22] and the novel replicative shuttle vector pAMYC (providing chloramphenicol resistance) were created (see below).

Table 1. Strains and plasmids used in this study.

\begin{tabular}{|c|c|c|}
\hline Strain/Plasmid & Relevant Characteristics & Reference or Source \\
\hline \multicolumn{3}{|l|}{ Strains } \\
\hline M. smegmatis $\mathrm{mc}^{2} 155$ & & [51] \\
\hline DH5a & E. coli cloning host & Laboratory stock \\
\hline ENSO & E. coli strain, his, formerly HfrG6D12 & {$[23]$} \\
\hline IBrpsO188:lacZ & ENS0 bearing E. coli rpsO'-'lacZ & [53] \\
\hline LAB_P ${ }_{\text {Eco }}$ rpsO ${ }_{\text {Msm }}: l a c Z$ & $\begin{array}{l}\text { ENSO bearing } M s m \text { rpsO'-'lacZ } \\
\text { under E. coli rpsO promoter }\end{array}$ & This paper \\
\hline Msm_PrpsOMsm:egfp & $\begin{array}{l}\text { M. smegmatis bearing } M s m \text { rpsO'-egfp } \\
\text { M. smegmatis bearing } M s m \text { rpsO'-egfp }\end{array}$ & This paper \\
\hline Msm_PrpsO ${ }_{\text {Msm }}: \operatorname{egfp}$ & $\begin{array}{l}\text { in the chromosome }\left(\operatorname{Kan}^{\mathrm{r}}\right) \text { under the } 5^{\prime} \\
\text { extended } r p s O \text { promoter }(-231) \\
\text { M. smegmatis bearing } M t b \text { rpsO'-egfp reporter }\end{array}$ & This paper \\
\hline Msm_PrpsO ${ }_{\mathrm{Mtb}}: \operatorname{egfp}$ & $\begin{array}{l}\text { in the chromosome }\left(\operatorname{Kan}^{\mathrm{r}}\right) \text { under the } \\
M t b \text { rpsO promoter }(-158)\end{array}$ & This paper \\
\hline \multicolumn{3}{|c|}{ 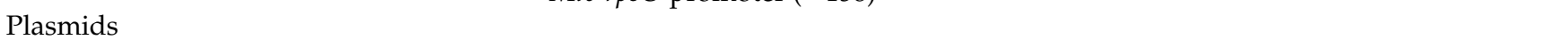 } \\
\hline pEMBL 46 & pEMBL8 ${ }^{+}$derivative lacking lacZ RBS & [23] \\
\hline $\mathrm{pES} 15_{M s m} \mathrm{TIR}(\mathrm{v} 1)$ & $\begin{array}{l}\text { pEMBL } 46 \text { derivative bearing } r p s O_{M s m}{ }^{\prime}-l a c Z \\
\text { reporter under the } M s m \text { core } r p s O \text { promoter }\end{array}$ & This paper \\
\hline $\mathrm{pES15}{ }_{M s m} \mathrm{TIR}(\mathrm{v} 2)$ & $\begin{array}{l}\text { pEMBL } 46 \text { derivative bearing } \operatorname{rpsO}_{M s m}{ }^{\prime}-' l a c Z \\
\text { reporter under the E. coli rpsO promoter }\end{array}$ & This paper \\
\hline pACYC184 & $\mathrm{Tet}^{\mathrm{r}}, \mathrm{Cm}^{\mathrm{r}}$, cloning vector & [54] \\
\hline pQE30_egfp & derivative of pQE30 (Qiagen) expressing the egfp gene & Lukyanov KA\# \\
\hline $\mathrm{pS} 15\left(\mathrm{pS} 15_{E c o}\right)$ & pACYC184 derivative expressing E. coli rpsO & [52] \\
\hline $\mathrm{pS} 15_{\mathrm{Msm}}(\mathrm{v} 1)$ & $\begin{array}{l}\text { pACYC184 derivative expressing } M s m \text { rpsO } \\
\text { under } M s m \text { rpsO core promoter and 5'UTR }\end{array}$ & This paper \\
\hline $\mathrm{pS} 15_{M s m}(\mathrm{v} 2)$ & $\begin{array}{l}\text { pACYC184 derivative expressing } M s m \text { rpsO } \\
\text { under E. coli rpsO promoter and Msm 5'UTR }\end{array}$ & This paper \\
\hline $\mathrm{pS} 15_{M s m}(\mathrm{v} 3)$ & $\begin{array}{l}\text { pACYC184 derivative expressing } M s m \text { rpsO } \\
\text { under E. coli rpsO promoter and } 5^{\prime} \mathrm{UTR} \text {-AUG }\end{array}$ & This paper \\
\hline pAMYC & pACYC184 derivative carrying oriM & This paper \\
\hline
\end{tabular}


Table 1. Cont

\begin{tabular}{|c|c|c|}
\hline Strain/Plasmid & Relevant Characteristics & Reference or Source \\
\hline pAMS15 ${ }_{M s m}$ & $\begin{array}{l}\text { pAMYC expressing } M s m \text { rpsO underthe } \mathrm{Msm} \text { rpsO } \\
5^{\prime} \text {-extended promoter }(-231)\end{array}$ & This paper \\
\hline pAMS15 ${ }_{E c o}$ & pAMYC expressing E. coli rpsO & This paper \\
\hline pMV261 & replicative shuttle vector, $\mathrm{Kan}^{\mathrm{r}}$ & [22] \\
\hline pMV306hsp & $\begin{array}{l}\text { integrative shuttle vector bearing } h s p 60 \text { promoter } \\
\text { and } r r n B \text { terminator, } \mathrm{Kan}^{\mathrm{r}} \\
\text { pMV306 derivatives bearing egfp fused with }\end{array}$ & [22] \\
\hline $\mathrm{pMVrpsO}_{M s m}:$ egfp & $\begin{array}{l}\text { Msm rpsO 5'UTR under rpsO promoters differing } \\
\text { in } 5^{\prime} \text { extensions }(-47,-117 \text { and }-231 \text { bp from TSS) } \\
\text { pMV306 derivative bearing egfp fused with }\end{array}$ & This paper \\
\hline pMVrpsO ${ }_{M s m}$ mut:egfp & $\begin{array}{l}\text { Msm rpsO 5'UTR harboring the mutated pseudoknot } \\
\text { under the } r p s O \text { extended }(-231) \text { promoter }\end{array}$ & This paper \\
\hline $\mathrm{pMVrpsO}_{M t b}: \operatorname{egfp}$ & $\begin{array}{l}\text { pMV306 derivative bearing egfp fused with } \\
M t b \text { rpsO 5'UTR under the } M t b \text { rpsO promoter }(-158)\end{array}$ & This paper \\
\hline
\end{tabular}

\# pQE30_egfp, a derivative of a standard vector pQE30 (Qiagen, Hilden, Germany) bearing the egfp gene cloned into MCS using BamHI and HindIII restriction sites, was provided by Prof. K.A. Lukyanov (Shemyakin-Ovchinnikov Institute of Bioorganic Chemistry RAS). The egfp gene encodes the enhanced green fluorescence protein (eGFP), an engineered mutant variant of the wild-type GFP, with brighter fluorescence.

\subsection{Construction of Expression Plasmids for Use in E. coli as a Surrogate Host}

To generate $\mathrm{pS} 15_{M s m}$ (v.1), the $r p s O$ gene, flanked with its own promoter and terminator sequences, was amplified by PCR on Msm genomic DNA with the primers Msm-rpsOfor 5'-ATCGGATCCGCACGATCCTGC and Msm-rpsO-rev 5'-ACTAAGCTTGCATGTCCG CAGAC. Forward and reverse primers comprised BamHI (for) and HindIII (rev) sites (bold italicized) for subsequent cloning in pACYC184. To create pS15 ${ }_{M s m}$ (v.2), the Msm rpsO promoter was replaced with the E. coli rpsO promoter by using a two-step PCR technique. First, two PCR fragments were obtained; one was amplified on pS15 Eco (a pACYC184 derivative bearing the E. coli rpsO gene flanked with its native promoter and terminator, see [53]), using the forward primer corresponding to the pACYC184 sequence, including the BamHI site (pACYC184-for 5'-CGATGCGTCCGGCGTAGAGGATCC) and the reverse primer (PrpsOmix-rev) comprising a sequence complementary both to the $E$. coli rpsO promoter/discriminator region and the beginning of the $\mathrm{Msm}$ rpsO transcript (5'-CATGCGCCGGATCGGCAGTATTCTACTC, with the Msm sequence underlined). Another PCR fragment was amplified on $\mathrm{pS} 15_{\mathrm{Msm}}$ (v.1) with the primers PrpsOmix-for, a complement of the PrpsOmix-rev (5'-GAGTAGAATACTGCCGATCCGGCGCATG where the Msm sequence is underlined, and the Eco_rpsO -10 promoter is in bold) and MsmrpsO-rev, described above. Second, the two PCR fragments were mixed and amplified with the external primers pACYC184-for and Msm-rpsO-rev; the resulting product was treated with BamHI and HindIII and cloned in pACYC184/BamHI, HindIII.

Lastly, to create $\mathrm{pS} 15_{\mathrm{Msm}}$ (v.3), not only the $\mathrm{Msm}$ rpsO promoter but also $5^{\prime}$-UTR and the start codon GUG were substituted for the corresponding E. coli sequences. As the first step, two PCR fragments were obtained: one amplified on $\mathrm{pS} 15_{E c o}$ with the primers pACYC184for (see above) and Eco-rpsOTIR-rev (5'-CGGCGGTAAGCGCCATTTTAAAACTCCAAAG, where the $M s m$ sequence is underlined), and another one amplified on $\mathrm{pS} 15_{M s m}$ (v.1) with the primers Eco-rpsOTIR-for (5'-CTTTGGAGTTTTAAAATGGCGCTTACCGCCG, where E. coli SD-sequence and AUG start codon are in bold, and the Msm rpsO sequence is underlined) and Msm-rpsO-rev. As the second step, the two PCR fragments were mixed and amplified in the presence of pACYC184-for and Msm-rpsO-rev; the resulting product was cloned in pACYC184, as described above. All three versions of $\mathrm{pS} 15_{\mathrm{Msm}}$ were sequenced and used for further experiments.

\subsection{Quantification of the In Vivo Transcripts by RT-qPCR with an Internal Standard}

The efficiency of the $\mathrm{Msm}$ rpsO gene expression in $E$. coli was evaluated by measuring the $\mathrm{Msm}$ rpsO transcript levels in cells bearing plasmids pS15 ${ }_{M s m}$ (versions 1, 2, 3) or the 
parental empty vector pACYC184 as a control. Total RNA was isolated by using the RNeasy mini kit (Qiagen, Hilden, Germany) according to recommendations of the manufacturer. Strains (including the control bearing an empty vector) were grown in $\mathrm{LB}$ medium at $37^{\circ} \mathrm{C}$, with vigorous shaking. At an optical density of $600 \mathrm{~nm}\left(\mathrm{OD}_{600}\right)$ of $\sim 0.4,2 \mathrm{~mL}$ aliquots of cell cultures were withdrawn and mixed with a $4 \mathrm{~mL}$ RNAprotect bacterial reagent. Next, total RNA was extracted; during extraction, RNase-free DNase was added to the columns for 15 min to eliminate DNA contaminations in RNA samples; after elution, RNA concentrations were estimated by measuring the $\mathrm{OD}_{260}$. Reverse transcription (RT) was performed with AMV reverse transcriptase (Promega Corporation, Madison, USA) in the final volume of $20 \mu \mathrm{L}$ for $1 \mathrm{~h}$ at $42{ }^{\circ} \mathrm{C}$ on $1 \mu \mathrm{g}$ of the total RNA in the presence of two reverse primers $(1 \mu \mathrm{L}$ of $5 \mu \mathrm{M}$ solution each) corresponding to the coding part of $\mathrm{Msm} r p s O$ (MsmrpsOcod-rev 5'-CGAGTGGTGATCGTGCTTGTGC) and to the reference gene rpoB (rpoBrev: 5'-CGGATTTGACATTCCTGGACGTC). Real-time PCR (qPCR) was run with the use of LightCycler 96 (Roche, Basel, Switzerland); each $25 \mu \mathrm{L}$ reaction contained $2 \mu \mathrm{L}$ of the RT mix, $5 \mu \mathrm{L} 5 \mathrm{x}$ qPCRmix HS SYBR (Evrogen, Moscow, Russia), forward primers corresponding to the beginning of transcripts (Msm-rpsOtr-for 5'-GTGGCTGTGTCGAGAATTTGTTCG for $\mathrm{pS} 15_{\mathrm{Msm}} \mathrm{v}$.1 and 2, Eco-rpsOtr-for 5'-GTAACGTACACTGGGATCGCTG for pS15 ${ }_{\mathrm{Msm}}$ v.3, rpoB-for 5'-ACGTCCACAAGTTCTGGATGTACC) and reverse primers used for RT ( $1 \mu \mathrm{L}$ of a $5 \mu \mathrm{M}$ solution each). Two independently isolated preparations of total RNA for each of the 4 strains were used for RT, and three technical replicates for each qPCR reaction were run simultaneously. Control qPCR reactions without RT were performed to exclude DNA contaminations in RNA preparations. LinRegPCR software was used to quantify transcript amounts relative to the reference transcript rpoB.

\subsection{Construction of the Msm_rpsO'-'lacZ Fusions Integrated into the E. coli Chromosome}

The $M s m \_r p s O^{\prime}$-' $l a c Z$ chromosomal fusions were generated, as previously described for different fusions related to the r-protein operons from $\gamma$-proteobacteria (see, e.g., [24,25]). For the fusion under the control of the Msm rpsO-promoter, a DNA fragment was amplified on pS15 ${ }_{\mathrm{Msm}} \mathrm{v} 1$ with the primers Msm-rpsO-for (see above) and Msm_TIR_rpsOrev 5'-GGAAGCTTTGGCCCAGGATCTC. The forward primer comprised the BamHI site, the reverse primer-HindIII (italicized in the sequence). The resulting fragment was cloned in pEMBL $\Delta 46 /$ BamHI, HindIII in frame with the lacZ open reading frame, then the correct construct was transferred onto the chromosome of ENS0 (Table) by homologous recombination, followed by the selection of the recombinant $\mathrm{Lac}^{+}$strains on McConkey agar. To substitute the $\mathrm{Msm}$ rpsO promoter with the E. coli counterpart, the corresponding DNA fragment was amplified on $\mathrm{pS} 15_{\mathrm{Msm}} \mathrm{v} 2$ with the primers $\mathrm{pACYC} 184$-for and Msm_TIR_rpsOrev (see above), cloned in pEMBL $\Delta 46 /$ BamHI, HindIII, and then transferred onto the chromosome of ENS0, as described above.

\subsection{Cell Growth and $\beta$-Galactosidase Assay}

E. coli cells bearing the Msm rpsO'-'lacZ reporters and the plasmid expressing Msm $\mathrm{S} 15$ or the empty vector were grown at $37^{\circ} \mathrm{C}$ in Luria-Bertani (LB) medium supplemented with chloramphenicol $(34 \mu \mathrm{g} / \mathrm{mL})$, harvested in exponential phase at $\mathrm{OD}_{600} \sim 0.4-0.5$, and used for the preparation of clarified cell lysates, essentially as described in [24]. The protein concentration in each fraction of the soluble proteins was determined by Bradford assay (Bio-Rad, Hercules, California, USA). Specific ß-galactosidase activities in the same fractions were measured according to Miller [55] and expressed in nmol ONPG (o-nitrophenyl- $\beta$-Dgalactopyranoside), hydrolyzed per minute per milligram of total soluble cell proteins.

3.6. Creation of the Novel Escherichia coli-Mycobacteria Shuttle Vector pAMYC, a Derivative of $p A C Y C 184$

A $3328 \mathrm{bp}$ - fragment of pACYC184 comprising genes for chloramphenicol $(\mathrm{Cm})$ and tetracycline (Tet) resistance as well as a replication origin p15A (oriE) was PCR-amplified by using Q5 High-Fidelity DNA Polymerase (New England Biolabs, Hitchin, Hertfordshire, UK) with the primers pACshtl- for (5'-TTCACGCGTAGCACCAGGCG, MluI restriction 
site italicized) and pACshtl-rev (5'-CTCCGCAAGAATTGATTGGCTCC). Mycobacterial origin of the replication (oriM) was amplified from pMV261 [24] by using Q5 DNA Polymerase and the primers oriM-for (5'-GCCTTTGAGTGAGCTGATACCG) and oriM-rev (5'-GATTTAAAGATCTGGTACCGCGGC), resulting in a 1976-bp PCR fragment. The PCR fragments (3328 and $1976 \mathrm{bp}$ in length) were gel-purified, treated with MluI (MluI site in the oriM-fragment is located near the annealing site for oriM-for), phosphorylated at blunt ends by treatment with T4-PNK (Thermo Scientific, Dreieich, Germany), and then ligated by T4-DNA ligase (Thermo Scientific, Dreieich, Germany) at room temperature. Ligation mix was used to transform $\mathrm{DH}-5 \alpha$ cells; plasmids were isolated from $\mathrm{Cm}^{\mathrm{r}}$ - transformants and used for electroporation of M. smegmatis cells [56]. Cm-resistant colonies appeared on LB-Cm agar plates after 3 days of incubation at $37^{\circ} \mathrm{C}$, indicating that a newly created plasmid (named pAMYC) indeed works as a mycobacteria-E. coli shuttle vector and may thus be used for cloning and expression in trans of mycobacterial proteins (or sRNAs, depending on the task) to study their effect on the expression of mycobacterial mRNA targets.

\subsection{Modification of the Integrative Plasmid $p M V 306 h s p$ to Provide Insertion of the rpsO-egfp Reporter Construct into the Chromosome of M. smegmatis}

The integrative shuttle vector pMV306hsp [22] carries the $h s p 60$ promoter and the $r r n B$ terminator to facilitate the cloning and expression of different genes as a single copy integrated into the chromosome. This plasmid was modified by deleting the region comprising the $h s p 60$ promoter and inserting the $r p s \mathrm{Osm}_{\mathrm{Ms}}$-egfp reporter in front of the $r \mathrm{rnB}$ terminator. To this end, pMV306hsp was treated with endonucleases MluI (upstream of the $h s p$ promoter) and HindIII (in front of the $r r n B$ terminator), and then dephosphorylated with TSAP (Thermosensitive Alkaline Phosphatase, Promega, Madison, WI, USA).

To generate inserts comprising the egfp reporter under the control of the Msm rpsO regulatory regions (including the promoter and $5^{\prime}$-UTR), the rpsO-egfp fusions were generated by the two-step PCR technique with overlapping primers. For the first fusion, the $\mathrm{Msm} r \mathrm{rsO}$ core promoter was used, $5^{\prime}$-end of which corresponded to the -47 position from the transcription start site (TSS). The $r p s O$ part was amplified from the M. smegmatis genomic DNA by using Tersus Plus PCR kit (Evrogen, Moscow, Russia) with primers (-47) rpsO-for (5'-CTAACGCGTTCCTGCGCGATTCTG, MluI site italicized) and rpsOegfp-rev (5'-CGCCCTTGCTCACCACGAAACAACTCCA). The egfp part was amplified from pQE30-egfp (Table), with primers rpsO-egfp-for (complementary to the rpsO-egfprev) and pQEegfp-rev (5'-GGAGTCCAAGCTCAGCTAATTAAGC, located downstream from HindIII site of pQE30-egfp). At the second step, the two PCR products were mixed and amplified with the external primers (-47) rpsO-for and pQE30egfp-rev, and the resulting product was cleaned from $2 \%$ agarose gel by Cleanup Standard Kit (Evrogen, Moscow, Russia), digested by MluI and HindIII, and ligated into pMV306/MluI, HindIII. The reporter constructs bearing $5^{\prime}$-extended $r p s O$ promoters were created in a similar way with the primers $(-117)$ rpsO-for (5'-TCTACGCGTAGGAGAAGTTCGATTC) and (-231) rpsO-for (5'-TGAACGCGTAATCCGACGTTCTC), while other primers were the same as described above.

The $r p s O-e g f p$ reporter construct bearing the $5^{\prime} \mathrm{UTR}$ and the $r p s O$ promoter from $M$. tuberculosis $(M t b)$ was created analogously. In this case, the promoter region was $5^{\prime}$-extended up to position -158 from TSS. Primers used for the two-step PCR: Mtb_rpsOfor (5'- AGAACGCGTTCGAATCGGTGCG, MluI site italicized), Mtb_rpsO-egfp-rev (5' CGCCCTTGCTCACGAAATGTCTCCATC), Mtb_rpsO-egfp-for (5'-GATGGAGACATTTC GTGAGCAAGGGCG, initiator GUG in bold) and pQEegfp-rev (see above). All amplification reactions were performed with the Tersus Plus PCR kit (Evrogen, Moscow, Russia).

\subsection{Mutagenesis of the Msm rpsO 5'UTR to Prevent Pseudoknot Formation}

To study the potential role of a pseudoknot within 5'UTR of the Msm rpsO mRNA in its expression and regulation, the sequence GGCCGCG involved in the pseudoknot 
formation was substituted for CCGGCGC (Figure 4B). To this end, a two-step PCR technique was used. First, two PCR products were obtained on the pMV306 derivative bearing the $\mathrm{Msm} r p s \mathrm{O}-\mathrm{e} g \mathrm{fp}$ fusion under the extended (-231) rpsO promoter with two pairs of primers: $\mathrm{P}(-231)$ rpsO-for_MluI 5' TGAACGCGTAATCCGACGTTCTC (MluI site underlined) with $\mathrm{rpsO}_{-}$mutPK- rev $5^{\prime}$ GCGCCGGTGCAGCATGCGCCGGATCG, and rpsO_mutPK- for $5^{\prime}$ CCGGCGCG GGCTGTGTCGAGAATTTG with egfp-HindIII- rev $5^{\prime}$ ATTAAGCTTTCACTTGTACAGCTCGTC (HindIII site underlined). -Second, the two PCR fragments were mixed and amplified in the presence of external primers $\mathrm{P}(-231) \mathrm{rpsO}$ for and egfp-HindIII- rev. The product was digested with MluI and HindIII and cloned into pMV306/MluI, HindIII. The resulting plasmid was sequenced and used to insert the mutated $r p s O-e g f p$ fusion (mutPK) into the Msm chromosome.

\subsection{Creating Plasmids for Ectopic Expression of the Msm (or E. coli) rpsO Gene in M. smegmatis}

To create the pAMYC derivative expressing Msm S15, the $r p s O$ gene flanked with the $5^{\prime}$ - extended promoter and terminator regions was amplified on the Msm genomic DNA by using Q5 DNA polymerase and primers $\mathrm{P}(-231)$ rpsO-for_BamHI bearing BamHI (5'-TGAGGATCCAATCCGACGTTCTC, BamHI in bold and italicized) and Msm-rpsO-rev (5'-ACTAAGCTTGCATGTCCGCAGAC, HindIII in bold and italicized). The PCR product was treated with BamHI /HindIII and then ligated into pAMYC treated with the same endonucleases. The ligation mix was used to transform E. coli; next, plasmids were isolated from Cm-resistant colonies, sequenced, and further used to transform Msm cells bearing the reporter Msm (or Mtb) rpsO-egfp. To create the pAMYC derivative expressing E. coli S15, the BamHI-HindIII fragment from pS15 Eco was cloned into pAMYC.

\subsection{Cell Growth and eGFP Assay}

Transformation-proficient M. smegmatis $\mathrm{mc}^{2} 155$ [51] was used for electroporation with pMV306 $\left(\mathrm{Kan}^{\mathrm{r}}\right)$ derivatives bearing the $r p s O-e g f p$ reporter genes to provide their insertion into the chromosome. The Kan ${ }^{\mathrm{r}}$-transformants were selected on LB-Kan agar plates, and then used for competent cell preparation and electroporation with an empty shuttle vector pAMYC, or with its derivatives carrying the Msm (or E. coli) rpsO gene for uS15 expression in trans (see above). The transformants were selected on LB-Kan-Cm agar plates, then grown at $37^{\circ} \mathrm{C}$ in LB supplemented with $34 \mu \mathrm{g} / \mathrm{mL} \mathrm{Cm}$ and $0.05 \%$ Tween 80 (to prevent cell clumping), and then harvested in exponential phase $\left(\mathrm{OD}_{600} \sim 0.7-0.8\right.$ ). Protein extracts were prepared as described in [57], with slight modifications. The cell pellets were resuspended in PBS and broken by using Beat Beater and $0.1 \mathrm{~mm}$ zircon beads (BioSpec Products Inc., Bartlesville, USA) (3 times for $30 \mathrm{~s}$ on ice, with 1:4 vol/vol ratio of beads to cell suspension). The cell lysates were clarified by centrifugation ( $20 \mathrm{~min}$, $12,000 \times \mathrm{g}$ rpm at $4{ }^{\circ} \mathrm{C}$ ), supernatants were treated with RQ-DNase (Promega, Madison, WI, USA) for $30 \mathrm{~min}$ on ice and used for the eGFP assay. Protein concentration in clarified lysates was determined by Bradford assay (Bio-Rad, Hercules, CA, USA). The enhanced green fluorescent protein (eGFP) has an excitation peak at $488 \mathrm{~nm}$ (blue light) and emits light maximally at $507 \mathrm{~nm}$ [58]. EGFP fluorescence in protein samples was measured in a 96-well microplate using Tecan Genios Pro fluorescence microplate reader (Tecan, Switzerland) and standard excitation-emission filters. The results were normalized to the protein concentration in samples. Each sample was obtained in at least three biological replicates. As a background control, protein lysates obtained from exponentially grown Msm cells were used.

Author Contributions: Conceptualization and designed the experiments, I.V.B. and L.V.A.; visualization, L.V.A.; investigation, L.V.A., L.S.K. and O.S.B.; methodology, L.V.A. and I.V.B.; writing-original draft preparation, I.V.B.; supervision, I.V.B.; funding acquisition, I.V.B. All authors have read and agreed to the published version of the manuscript.

Funding: This research was funded by Russian Foundation for Basic Research, grant No. 18-04-00743.

Institutional Review Board Statement: Not applicable. 
Informed Consent Statement: Not applicable.

Data Availability Statement: Not applicable.

Acknowledgments: We thank Elena Salina for kindly providing the genomic DNA from M. tuberculosis and Konstantin Lukyanov for the plasmid pQE30_egfp. We are grateful to Tatyana Azhikina, Yulia Skvortzova, and Artem Grigorov for the helpful discussion.

Conflicts of Interest: The authors declare no conflict of interest.

\section{References}

1. Nomura, M.; Gourse, R.; Baughman, G. Regulation of the synthesis of ribosomes and ribosomal components. Ann. Rev. Biochem. 1984, 53, 75-117. [CrossRef]

2. Zengel, J.M.; Lindahl, L. Diverse mechanisms for regulating ribosomal protein synthesis in Escherichia coli.. Prog. Nucleic Acid Res. Mol. Biol. 1994, 47, 331-370. [CrossRef]

3. Fu, Y.; Deiorio-Haggar, K.; Anthony, J.; Meyer, M.M. Most RNAs regulating ribosomal protein biosynthesis in Escherichia coli are narrowly distributed to Gammaproteobacteria. Nucleic Acids Res. 2013, 41, 3491-3503. [CrossRef]

4. Babina, A.M.; Parker, D.J.; Li, G.W.; Meyer, M.M. Fitness advantages conferred by the L20-interacting RNA cis-regulator of ribosomal protein synthesis in Bacillus subtilis. RNA 2018, 24, 1133-1143. [CrossRef]

5. Babina, A.M.; Soo, M.W.; Fu, Y.; Meyer, M.M. An S6:S18 complex inhibits translation of E. coli rpsF. RNA 2015, 21, 2039-2046. [CrossRef] [PubMed]

6. Aseev, L.V.; Bylinkina, N.S.; Boni, I.V. Regulation of the rplY gene encoding 5S rRNA binding protein L25 in Escherichia coli and related bacteria. RNA 2015, 21, 851-861. [CrossRef]

7. Aseev, L.V.; Koledinskaya, L.S.; Boni, I.V. Regulation of ribosomal protein operons rplM-rpsI, rpmB-rpmG, and rplU-rpmA at the transcriptional and translational levels. J. Bacteriol. 2016, 198, 2494-2502. [CrossRef]

8. Aseev, L.V.; Koledinskaya, L.S.; Boni, I.V. Autogenous regulation in vivo of the rpmE gene encoding ribosomal protein L31 (bL31), a key component of the protein-protein intersubunit bridge B1b. RNA 2020, 26, 814-826. [CrossRef]

9. Philippe, C.; Eyermann, F.; Benard, L.; Portier, C.; Ehresmann, B.; Ehresmann, C. Ribosomal protein S15 from Escherichia coli modulates its own translation by trapping the ribosome on the mRNA initiation loading site. Proc. Natl. Acad. Sci. USA 1993, 90, 4394-4398. [CrossRef]

10. Ehresmann, C.; Philippe, C.; Westhof, E.; Benard, L.; Portier, C.; Ehresmann, B. A pseudoknot is required for efficient translation initiation and regulation of the E. coli rpsO gene coding for ribosomal protein S15. Biochem. Cell Biol. 1995, 73, 1131-1140. [CrossRef]

11. Bénard, L.; Mathy, N.; Grunberg-Manago, M.; Ehresmann, B.; Ehresmann, C.; Portier, C. Identification in a pseudoknot of a U.G motif essential for the regulation of the expression of ribosomal protein S15. Proc. Natl. Acad. Sci. USA 1998, 95, $2564-2567$. [CrossRef]

12. Serganov, A.; Ennifar, E.; Portier, C.; Ehresmann, B.; Ehresmann, C. Do mRNA and rRNA binding sites of E. coli ribosomal protein S15 share common structural determinants? J. Mol. Biol. 2002, 320, 963-978. [CrossRef]

13. Mathy, N.; Pellegrini, O.; Serganov, A.; Patel, D.J.; Ehresmann, C.; Portier, C. Specific recognition of $r p s O$ mRNA and $16 S$ rRNA by Escherichia coli ribosomal protein S15 relies on both mimicry and site differentiation. Mol. Microbiol. 2004, 52, 661-675. [CrossRef]

14. Marzi, S.; Myasnikov, A.G.; Serganov, A.; Ehresmann, C.; Romby, P.; Yusupov, M.; Klaholz, B.P. Structured mRNAs regulate translation initiation by binding to the platform of the ribosome. Cell 2007, 130, 1019-1031. [CrossRef]

15. Scott, L.G.; Williamson, J.R. Interaction of the Bacillus stearothermophilus ribosomal protein S15 with its 5'-translational operator mRNA. J. Mol. Biol. 2001, 314, 413-422. [CrossRef]

16. Scott, L.G.; Williamson, J.R. The binding interface between Bacillus stearothermophilus ribosomal protein S15 and its 5'-translational operator mRNA. J. Mol. Biol. 2005, 351, 280-290. [CrossRef]

17. Slinger, B.L.; Meyer, M.M. RNA regulators responding to ribosomal protein S15 are frequent in sequence space. Nucleic Acids Res. 2016, 44, 9331-9341. [CrossRef]

18. Serganov, A.; Polonskaia, A.; Ehresmann, B.; Ehresmann, C.; Patel, D.J. Ribosomal protein S15 represses its own translation via adaptation of an rRNA-like fold within its mRNA. EMBO J. 2003, 22, 1898-1908. [CrossRef]

19. Slinger, B.L.; Deiorio-Haggar, K.; Anthony, J.S.; Gilligan, M.M.; Meyer, M.M. Discovery and validation of novel and distinct RNA regulators for ribosomal protein S15 in diverse bacterial phyla. BMC Genom. 2014, 15, 657. [CrossRef]

20. Slinger, B.L.; Newman, H.; Lee, Y.; Pei, S.; Meyer, M.M. Coevolution of bacterial ribosomal protein S15 with diverse mRNA regulatory structures. PLoS Genet. 2015, 11, e1005720. [CrossRef]

21. Bashiri, G.; Baker, E.N. Production of recombinant proteins in Mycobacterium smegmatis for structural and functional studies. Protein Sci. 2015, 24, 1-10. [CrossRef]

22. Stover, C.K.; de la Cruz, V.F.; Fuerst, T.R.; Burlein, J.E.; Benson, L.A.; Bennett, L.T.; Bansal, G.P.; Young, J.F.; Lee, M.H.; Hatfull, G.F.; et al. New use of BCG for recombinant vaccines. Nature 1991, 351, 456-460. [CrossRef]

23. Dreyfus, M. What constitutes the signal for the initiation of protein synthesis on Escherichia coli mRNAs? J. Mol. Biol. 1988, 204, 79-94. [CrossRef] 
24. Tchufistova, L.S.; Komarova, A.V.; Boni, I.V. A key role for the mRNA leader structure in translational control of ribosomal protein S1 synthesis in $\gamma$-proteobacteria. Nucleic Acids Res. 2003, 31, 6996-7002. [CrossRef] [PubMed]

25. Aseev, L.V.; Levandovskaya, A.A.; Skaptsova, N.V.; Boni, I.V. Conservation of regulatory elements controlling the expression of the rpsB-tsf operon in $\gamma$-proteobacteria. Mol. Biol. 2009, 43, 101-107. [CrossRef]

26. Bashyam, M.D.; Tyagi, A.K. Identification and analysis of "extended -10" promoters from mycobacteria. J. Bacteriol. 1998, 180, 2568-2573. [CrossRef]

27. Arnvig, K.B.; Gopal, B.; Papavinasasundaram, K.G.; Cox, R.A.; Colston, M.J. The mechanism of upstream activation in the rrnB operon of Mycobacterium smegmatis is different from the Escherichia coli paradigm. Microbiology 2005, 151, 467-473. [CrossRef]

28. Agarwal, N.; Tyagi, A.K. Mycobacterial transcriptional signals: Requirements for recognition by RNA polymerase and optimal transcriptional activity. Nucleic Acids Res. 2006, 34, 4245-4257. [CrossRef]

29. Satchidanandam, V.; Amara, R.R.; Uchil, P.D.; Singh, V. The regulatory elements of the Mycobacterium tuberculosis gene Rv3881c function efficiently in Escherichia coli. FEMS Microbiol. Lett. 2003, 218, 365-370. [CrossRef]

30. Cortes, T.; Cox, R.A. Transcription and translation of the rpsJ, rplN and rRNA operons of the tubercle bacillus. Microbiology 2015, 161, 719-728. [CrossRef]

31. Sawyer, E.B.; Grabowska, A.D.; Cortes, T. Translation regulation in mycobacteria and its implications for pathogenicity. Nucleic Acids Res. 2018, 46, 6950-6961. [CrossRef]

32. Sawyer, E.B.; Phelan, J.E.; Clark, T.G.; Cortes, T. A snapshot of translation in Mycobacterium tuberculosis during exponential growth and nutrient starvation revealed by ribosome profiling. Cell Rep. 2021, 34, 108695. [CrossRef]

33. Srivastava, A.; Asahara, H.; Zhang, M.; Zhang, W.; Liu, H.; Cui, S.; Jin, Q.; Chong, S. Reconstitution of protein translation of Mycobacterium reveals functional conservation and divergence with the Gram-negative bacterium Escherichia coli. PLoS ONE 2016, 11, e0162020. [CrossRef]

34. Newton-Foot, M.; Gey van Pittius, N.C. The complex architecture of mycobacterial promoters. Tuberculosis 2013, 93, 60-74. [CrossRef] [PubMed]

35. Cortes, T.; Schubert, O.T.; Rose, G.; Arnvig, K.B.; Comas, I.; Aebersold, R.; Douglas, B. Genome-wide mapping of transcriptional start sites defines an extensive leaderless transcriptome in Mycobacterium tuberculosis. Cell Rep. 2013, 5, 1121-1131. [CrossRef] [PubMed]

36. Aseev, L.V.; Koledinskaya, L.S.; Boni, I.V. Dissecting the extended "-10" Escherichia coli rpsB promoter activity and regulation in vivo. Biochemistry 2014, 79, 776-784. [CrossRef] [PubMed]

37. Bon, M.; Micheletti, C.; Orland, H. McGenus: A Monte Carlo algorithm to predict RNA secondary structures with pseudoknots. Nucleic Acids Res. 2013, 41, 1895-1900. [CrossRef]

38. Conn, A.B.; Diggs, S.; Tam, T.K.; Blaha, G.M. Two old dogs, one new trick: A review of RNA polymerase and ribosome interactions during transcription-translation coupling. Int. J. Mol. Sci. 2019, 20, 2595. [CrossRef]

39. Chen, M.; Fredrick, K. RNA polymerase's relationship with the ribosome: Not so physical, most of the time. J. Mol. Biol. 2020, 432, 3981-3986. [CrossRef] [PubMed]

40. Boni, I.V.; Isaeva, D.M.; Musychenko, M.L.; Tzareva, N.V. Ribosome-messenger recognition: mRNA target sites for ribosomal protein S1. Nucleic Acids Res. 1991, 19, 155-162. [CrossRef]

41. Komarova, A.V.; Tchufistova, L.S.; Supina, E.V.; Boni, I.V. Protein S1 counteracts the inhibitory effect of the extended ShineDalgarno sequence on translation. RNA 2002, 8, 1137-1147. [CrossRef]

42. Duval, M.; Korepanov, A.; Fuchsbauer, O.; Fechter, P.; Haller, A.; Fabbretti, A.; Choulier, L.; Micura, R.; Klaholz, B.P.; Romby, P.; et al. Escherichia coli ribosomal protein S1 unfolds structured mRNAs onto the ribosome for active translation initiation. PLoS Biol. 2013, 11, e1001731. [CrossRef]

43. Lund, P.E.; Chatterjee, S.; Daher, M.; Walter, N.G. Protein unties the pseudoknot: S1-mediated unfolding of RNA higher order structure. Nucleic Acids Res. 2020, 48, 2107-2125. [CrossRef] [PubMed]

44. Bernstein, J.R.; Bulter, T.; Shen, C.R.; Liao, J.C. Directed evolution of ribosomal protein S1 for enhanced translational efficiency of high GC Rhodopseudomonas palustris DNA in Escherichia coli. J. Biol. Chem. 2007, 282, 18929-18936. [CrossRef]

45. McGuffin, L.J.; Adiyaman, R.; Maghrabi, A.H.A.; Shuid, A.N.; Brackenridge, D.A.; Nealon, J.O.; Philomina, L.S. IntFOLD: An integrated web resource for high performance protein structure and function prediction. Nucleic Acids Res. 2019, 47, W408-W413. [CrossRef] [PubMed]

46. Wu, Y.J.; Wu, C.H.; Yeh, A.Y.; Wen, J.D. Folding a stable RNA pseudoknot through rearrangement of two hairpin structures. Nucleic Acids Res. 2014, 42, 4505-4515. [CrossRef] [PubMed]

47. Šiková, M.; Janoušková, M.; Ramaniuk, O.; Páleníková, P.; Pospíšil, J.; Bartl, P.; Suder, A.; Pajer, P.; Kubičková, P.; Pavliš, O.; et al. Ms1 RNA increases the amount of RNA polymerase in Mycobacterium smegmatis. Mol. Microbiol. 2019, 11, 354-372. [CrossRef]

48. Gerrick, E.R.; Barbier, T.; Chase, M.R.; Xu, R.; François, J.; Lin, V.H.; Szucs, M.J.; Rock, J.M.; Ahmad, R.; Tjaden, B.; et al. Small RNA profiling in Mycobacterium tuberculosis identifies MrsI as necessary for an anticipatory iron sparing response. Proc. Natl. Acad. Sci. USA 2018, 115, 6464-6469. [CrossRef] [PubMed]

49. Li, X.; Mei, H.; Chen, F.; Tang, Q.; Yu, Z.; Cao, X.; Andongma, B.T.; Chou, S.H.; He, J. Transcriptome landscape of Mycobacterium smegmatis. Front. Microbiol. 2017, 8, 2505. [CrossRef]

50. Kapopoulou, A.; Lew, J.M.; Cole, S.T. The MycoBrowser portal: A comprehensive and manually annotated resource for mycobacterial genomes. Tuberculosis 2011, 91, 8-13. [CrossRef] 
51. Snapper, S.B.; Melton, R.E.; Mustafa, S.; Kieser, T.; Jacobs, J.W.R. Isolation and characterization of efficient plasmid transformation mutants of Mycobacterium smegmatis. Mol. Microbiol. 1990, 4, 1911-1919. [CrossRef] [PubMed]

52. Belisle, J.T.; Mahaffey, S.B.; Hill, P.J. Isolation of mycobacterium species genomic DNA. Methods Mol. Biol. 2009, 465, 1-12. [CrossRef] [PubMed]

53. Le Derout, J.; Boni, I.V.; Regnier, P.; Hajnsdorf, E. Hfq affects mRNA levels independently of degradation. BMC Mol. Biol. 2010, 11, 17. [CrossRef] [PubMed]

54. Chang, A.C.; Cohen, S.N. Construction and characterization of amplifiable multicopy DNA cloning vehicles derived from the P15A cryptic miniplasmid. J. Bacteriol. 1978, 134, 1141-1156. [CrossRef]

55. Miller, J.H. Experiments in Molecular Genetics; Cold Spring Harbor Laboratory Press: Cold Spring Harbor, NY, USA, 1972.

56. Goude, R.; Roberts, D.M.; Parish, T. Electroporation in mycobacteria. In Mycobacteria Protocols. Methods in Molecular Biology; Parish, T., Roberts, D.M., Eds.; Springer Science+ Business Media: New York, NY, USA, 2015; Volume 1285. [CrossRef]

57. Rabodoarivelo, M.S.; Aerts, M.; Vandamme, P.; Palomino, J.C.; Rasolofo, V.; Martin, A. Optimizing of a protein extraction method for Mycobacterium tuberculosis proteome analysis using mass spectrometry. J. Microbiol. Methods 2016, 131, 144-147. [CrossRef]

58. Cormack, B.P.; Valdiva, R.H.; Falkow, S. FACS-optimized mutants of the green fluorescent protein (GFP) . Gene 1996, 173, 33-38. [CrossRef] 